\section{ACERCA DE LA BIOTECNOLOGÍA AMBIENTAL}

\author{
Rafael Blasco Pla \\ Universidad de Extremadura \\ rblasco@unex.es \\ Francisco Castillo Rodríguez \\ biocastillo2@gmail.com
}

Cómo citar este artículo/Citation: Blasco Pla, R. y Castillo Rodríguez, F. (2014). "Acerca de la biotecnología ambiental". Arbor, 190 (768): a157. doi: http://dx.doi.org/10.3989/ arbor.2014.768n4011

Recibido: 9 junio 2014. Aceptado: 14 julio 2014.

RESUMEN: La Biotecnología ambiental trata de corregir los desequilibrios causados en el medio ambiente por actividades industriales que alteran los ecosistemas naturales mediante contaminación química o biológica y que también afectan a los grandes ciclos biogeoquímicos en la biosfera, mayoritariamente catalizados por seres vivos, entre los que los microrganismos juegan un papel esencial. Las desviaciones en los balances de compuestos carbonados, nitrogenados y azufrados atmosféricos pueden causar fenómenos de gran complejidad como el calentamiento global, la destrucción de la capa de ozono, la contaminación ambiental o la Iluvia ácida. Por otra parte, las interacciones de los microorganismos entre sí y con el medio, desconocidas en su mayor parte, tiene importantes repercusiones en la generación y persistencia de especies químicas que, depositadas en las cadenas tróficas, son altamente tóxicas para los organismos vivos. Para atajar estos problemas es necesario avanzar en el conocimiento a nivel molecular de la ecología microbiana y del funcionamiento de los ciclos biogeoquímicos, aunque no es menos necesario desarrollar tecnologías para la eliminación de contaminantes industriales in situ y ex situ, evitar su producción y utilización incontroladas así como corregir las actuaciones desequilibrantes, actuales o futuras, de la biogeoquímica planetaria.

PALABRAS CLAVE: Biorremediación; ciclos biogeoquímicos; biocombustibles; célula de combustible microbiana; pilas bioelectroquímicas.

\section{ENVIRONMENTAL BIOTECHNOLOGY}

Copyright: (C) 2014 CSIC. Este es un artículo de acceso abierto distribuido bajo los términos de la licencia Creative Commons Attribution-Non Commercial (by-nc) Spain 3.0.
ABSTRACT: The aim of environmental biotecnology is to correct environmental imbalances caused by modern industrial activities. Many of these imbalances affect biogeochemical cycles in the biosphere, mainly catalysed by microorganisms. Deviations in the balances of carbon, nitrogen, sulphur and iron compounds may cause very complex phenomena such as global warming, destruction of the ozone layer, environmental pollution and acidification of the sea. On the other hand, the poorly understood microbial interactions --either with each other or the environment-- have important consequences in generating highly recalcitrant chemical species which, accumulating in the trophic chains, are highly toxic for living organisms. To cope with these problems it is necessary to improve knowledge of microbial ecology and the functioning of the biogeochemical cycles at the molecular level, although it is also worth designing technologies to eliminate pollutants either in situ or ex situ, to avoid its uncontrolled production as well as to correct the unbalancing processes affecting phases of the biogeochemical cycles, either in the present day or in the future.

KEYWORDS: Biorremediation; biogeochemical cycles; biofuels; microbial fuel cells; bioelectrochemical cells. 


\section{INTRODUCCIÓN}

El término biotecnología es una miscelánea con el denominador común de utilizar seres vivos, o parte de ellos, para uso humano. De esta definición habría que excluir animales y plantas, tanto naturales como mejoradas por métodos naturales de cruzamiento, ya que en tal caso se trataría de la agricultura y la ganadería clásicas, cuya aparición hace 10.000 años constituyó la primera revolución verde. Se suele hablar de biotecnología de animales y plantas cuando estos han sido manipulados genéticamente. En el caso de los microorganismos, la biotecnología incluye tanto cepas naturales como microorganismos manipulados genéticamente, cuya utilización en bio-reactores se puede denominar también microbiología industrial, bioquímica industrial o ingeniería bioquímica/biotecnológica. Cuando los bio-reactores se emplean para eliminar residuos, la biotecnología está claramente al servicio del cuidado del medio ambiente, ya que evita su contaminación. Además, en muchos casos, los bioreactores proporcionan productos con un valor añadido que los hace sostenibles. Atendiendo al ser vivo objeto de la biotecnología se clasifica en biotecnología de microorganismos, de animales o de plantas, casi siempre con el matiz de su mejora artificial con un fin concreto que se emplea para clasificar a la biotecnología sobre la base de nombres o colores. Así, a la biotecnología sanitaria se le suele asignar el color rojo, a la de los alimentos el amarillo, a la del mar el azul, a la industrial el blanco, etc. (DaSilva, 2004). El color verde puede agrupar la biotecnología ambiental y la de plantas, aunque hay quien aplica el verde solo a las plantas relegando la biotecnología ambiental al discreto gris. El uso de los colores se justifica en la necesidad de clasificar y simplificar, de cara a la sociedad, los usos de la biotecnología, aunque aumentar el número de colores y matices puede ser contraproducente y puede resultar confuso mezclar criterios a la hora de clasificar. Por ejemplo, a biotecnología microbiana se puede emplear tanto en la industria farmacéutica (rojo) como en la eliminación de contaminantes (verde o gris), en la fabricación de alimentos (amarillo), etc. En cuanto a la biotecnología ambiental, el color adecuado sería el verde, junto con la de plantas, porque la biotecnología de plantas, además de muchas otras aplicaciones, es clave en la biotecnología ambiental.

Hasta ahora se han descrito nueve procesos amenazados de grave desequilibrio a nivel planetario, que constituyen lo que se denominan Planetary Boundaries y que se enumeran a continuación en orden de mayor a menor importancia: pérdida de biodiversidad, ciclos del nitrógeno y fósforo, cambio climático, acidificación oceánica, calidad de las aguas continentales, usos agrícolas, descarga de aerosoles en la atmósfera, capa de ozono atmosférica y contaminación química. Si se sobrepasan los valores admitidos como frontera, se pueden generar desequilibrios que pueden afectar no solo a uno de tales procesos en sí, sino también a los demás dado que la mayoría de ellos presentan fuertes interrelaciones. Así, un desequilibrio en el ciclo del nitrógeno afecta al balance entre las diferentes formas de este elemento en la naturaleza, pero también a la calidad de las aguas, la contaminación química, la capa de ozono o la lluvia ácida. Para mantener estos procesos u otros que, aunque menos importantes a nivel global sí pueden serlo a nivel local, dentro de límites aceptables, es necesario conocerlos muy bien desde los puntos de vista microbiológico, bioquímico, genético, evolutivo y ecológico, conocimiento que hoy por hoy es absolutamente insatisfactorio.

En el presente artículo, los autores pretenden dar una visión actualizada de la biogeoquímica planetaria, haciendo hincapié en las etapas de la misma que se encuentran en desequilibrio o en fase de estarlo. Por otra parte, se examinarán las biotecnologías encaminadas a corregir estos desequilibrios y que abarcan desde actuaciones directas sobre el medio ambiente al diseño de dispositivos de última generación como los que utilizan microorganismos para generar electricidad o combustibles como $\mathrm{H}_{2} \circ \mathrm{NH}_{3}$, proceder a la eliminación de contaminantes in situ o ex situ, diseñar nuevos materiales basados en los nanocables y otras aplicaciones que entran dentro del campo de la Biotecnología, sin pretender la exhaustividad que solo puede obtenerse mediante una extensa monografía (Castillo et al., 2005).

\section{CONCEPTOS FUNDAMENTALES}

Si se puede definir la contaminación ambiental como el desequilibrio puntual ocasionado en un determinado proceso natural, sea este un ciclo biogeoquímico o un medio natural terrestre, acuático o atmosférico, y la función de la Biotecnología ambiental es corregir estos desequilibrios, parece evidente que es necesario que el biotecnólogo conozca en profundidad tanto los ciclos como los seres vivos que operan en ellos y, en especial, los microorganismos, principales catalizadores de la biogeoquímica planetaria. En la actualidad, la genómica ambiental, y en especial la metagenómica, ha revelado que se está muy lejos de conocer en profundidad la biodiversidad microbiana y solo con el uso de los meta-análisis genó- 
micos, físico-químicos y metabólicos, que se valen de las técnicas ómicas (genómica y metagenómica, transcriptómica, metabolómica, microbiómica, etc.), de la bioinformática, la biología de sistemas y de las nuevas tecnologías de identificación in situ, está emergiendo una visión más adecuada y realista del problema (Simon y Daniel, 2011).

Los seres vivos son sistemas necesariamente abiertos que requieren un aporte continuo de energía y de materia. Los ciclos biogeoquímicos existen porque la cantidad de materia (elementos químicos) disponible para los seres vivos en la Tierra, sistema cerrado en la actualidad, es limitada, y por lo tanto es necesario reutilizarla. La biodegradación de contaminantes, que es quizá la parte más conocida de la biotecnología ambiental, consiste en la utilización de microorganismos para transformar los compuestos químicos en biomasa microbiana, aunque a veces solo se transforman en otros (cometabolismo). Por lo tanto, es necesario conocer la formula empírica, o composición elemental, de la biomasa para procurar que exista la relación adecuada, estequiométrica, de los diferentes elementos químicos (C/N/P/S) y oligoelementos que permitan los procesos biodegradativos tanto in situ como ex situ. A la vez, los intermediarios químicos de los ciclos biogeoquímicos están conectados por reacciones catalizadas por microorganismos, cada una de las cuales suele consistir en un par de oxidorreducción (redox). Esta semi-reacción, junto con otro par, debe completar una reacción redox que suministre la energía necesaria para el proceso vital. En definitiva, también se trata de una cuestión termodinámica ya que el proceso tiene que ser exergónico en su conjunto, pero puede ocurrir, como en el metabolismo, que un determinado microorganismo viva a expensas de un proceso endergónico que solo es viable acoplado a otro muy exergónico, catalizado por otro u otros microorganismos. Este fenómeno, muy común en la naturaleza, se denomina sintrofia y su ubicuidad natural hace que muchos microorganismos no sean fácilmente cultivables en el laboratorio.

Para poder actuar sobre la contaminación ambiental se requiere el conocimiento de la ecología microbiana, de los ciclos biogeoquímicos y de las limitaciones tanto termodinámicas como estequiométricas de sus etapas. Así se podrá actuar sobre el componente cinético, constituido por los microorganismos que catalizan el proceso. La biotecnología puede incidir en la disposición de consorcios microbianos de alta potencia catabólica gracias a la sintrofia, la adición al medio de co-sustratos inocuos que faciliten la biodegradación al activar enzimas presentes en comunidades microbianas preexistentes pero en estado latente, etc. Estas tecnologías se han revelado más o menos eficaces en el tratamiento de problemas concretos de contaminación ambiental, como en el caso del vertido masivo de crudos y otros compuestos naturales. Sin embargo, algunos compuestos xenobióticos no son fácilmente biodegradables. Es más, se ha demostrado que el metabolismo de algunos compuestos xenobióticos por bacterias normalmente presentes en el suelo puede producir compuestos más tóxicos que los originales (Blasco et al., 1995). Resultados como este justifican la construcción racional, por ingeniería genética, de nuevas cepas con rutas híbridas que eviten la formación de intermediarios tóxicos, que podrían ser dotadas de sistemas de autocontención para evitar su posible expansión (Munthali et al., 1996).

\section{LOS GRANDES CICLOS BIOGEOQUÍMICOS}

\subsection{El ciclo del carbono}

En la naturaleza, el carbono está en la atmósfera $\left(0,7\right.$ teratoneladas, Tt o $10^{12}$ toneladas), los océanos (38 Tt), la litosfera (carbonatos $60.000 \mathrm{Tt}$, kerógeno $14.000 \mathrm{Tt}$ ), la biosfera (2 Tt) y los combustibles fósiles (4 Tt). El carbono se encuentra en varios estados de reducción, desde el más oxidado $(+4)$ en el $\mathrm{CO}_{2}$ hasta el más reducido (-4) en el $\mathrm{CH}_{4}$ (Figura 1). Entre estos dos estados extremos existen formas como el $\mathrm{CO}$, los fragmentos monocarbonados metenilo $(=\mathrm{CH}-$ ), metileno $\left(=\mathrm{CH}_{2}\right)$, metilo $\left(-\mathrm{CH}_{3}\right)$, formimino $(-\mathrm{HC}=\mathrm{NH})$ y formilo $(-\mathrm{HC}=\mathrm{O})$, intermediarios metabólicos en la carboxidotrofia, la metanogénesis, la metanotrofia, el metabolismo de aminoácidos y la ruta del Acetil-CoA. Otros intermediarios metabólicos son los del catabolismo y anabolismo de azúcares, lípidos, proteínas y los miles de compuestos carbonados generados por la factoría biosintética vegetal y microbiana y, en la actualidad, por la industria químico-farmacéutica. Las rutas metabólicas del fragmento monocarbonado son muy importantes en el ciclo del carbono y requieren coenzimas comunes, como los folatos o la cobalamina o más exóticas como la metanopterina, la coenzima M (2-mercaptoetanosulfonato), la coenzima B (fosfato de 7-tioheptanoiltreonina), la F420 (5-deazaflavina) y la F430 (un anillo tetrapirrólico, muy reducido, con níquel, abundante en las arqueobacterias ANME que catalizan la oxidación anaeróbica de metano en sintrofia con la reducción de sulfato). Un grupo monocarbonado no menos importante es el grupo carboxilo, donde el carbono posee un estado de oxidación de +4 , muy abundante en los intermediarios metabólicos y absolutamente clave en la fijación biológica del $\mathrm{CO}_{2}$ ya sea fotosintética o no. 
Figura 1. El ciclo del carbono en la biosfera

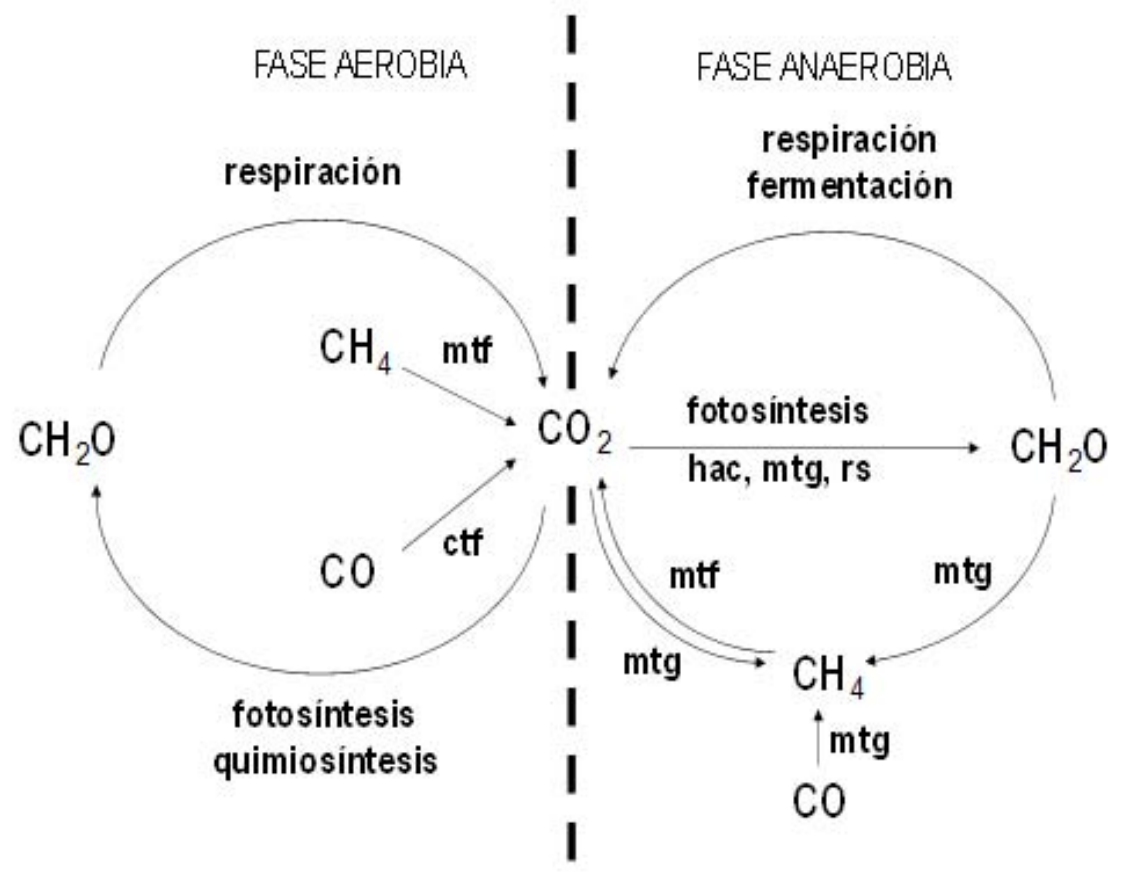

La línea de puntos separa las reacciones que tienen lugar en presencia de oxígeno (izquierda) de las que tienen lugar en anaerobiosis (derecha). Los catalizadores de los ciclos están abreviados como mtf (metanotrofos y metilotrofos), ctf (carboxidotrofos), hac (homoacetógenos), mtg (metanógenos), rs (reductores de sulfato)

El $\mathrm{CO}_{2}$, el $\mathrm{CH}_{4}$ y los CFC ejercen un fuerte efecto invernadero, también debido a otros gases atmosféricos como el $\mathrm{N}_{2} \mathrm{O}$, el $\mathrm{O}_{3}$ y el propio vapor de agua, debido a que absorben la radiación de 4000-24000 $\mathrm{nm}$ emitida por la superficie terrestre, lo que genera un calentamiento global del planeta. Este fenómeno, previsto por Joseph Fourier en 1824, fue descubierto en 1860 por John Tyndall, estudiado cuantitativamente por Svante Arrhenius en 1896 y sacado a la luz pública por Guy Stewart Callendar en 1960, el denominado efecto Callendar, al que en principio achacó un efecto beneficioso y no perjudicial. Los estudios paleoclimáticos han revelado episodios de cambio climático global, el denominado PEMT, aunque lento por ser debido a causas naturales como emisiones de $\mathrm{CH}_{4}$ acumulado como hidrato en el manto terrestre (Pancost et al., 2007). Por otra parte, el seguimiento del clima desde épocas históricas hasta la actualidad ha revelado que existe una tendencia al aumento de temperatura, relativamente rápido en este caso por ser presuntamente debido a causas antropogénicas (Pla y Catalan, 2005).

El desarrollo de la humanidad requiere un crecimiento exponencial de la demanda energética, en buena parte procedente de combustibles fósiles.
Si en un intervalo de décadas se quema la materia orgánica (metano, carbón y petróleo) que ha necesitado tiempo a escala geológica para formarse, es evidente que se desequilibra el ciclo del carbono al incrementar la concentración de $\mathrm{CO}_{2}$ atmosférico. El efecto invernadero debido a este provoca un aumento de la temperatura y una acidificación de los océanos, principal sumidero del $\mathrm{CO}_{2}$, de consecuencias imprevisibles. Cualquier actuación biotecnológica para solucionar este problema mejoraría el medio ambiente y por tanto se puede considerar parte de la biotecnología ambiental.

El ciclo del carbono se puede re-equilibrar de varias maneras, la más evidente es utilizar combustibles cuya materia orgánica provenga de la fijación de $\mathrm{CO}_{2}$ atmosférico, normalmente de la fotosíntesis. La quema de madera ya se hacía en la era pre-industrial, pero los biocombustibles son productos más elaborados, cuyo carbono procede también de la fotosíntesis. El bioetanol y el biodiesel se utilizan actualmente porque se pueden adaptar a los motores de combustión interna. El bioetanol procede de la destilación del alcohol obtenido por fermentación de azúcares, mientras que el biodiesel procede de las grasas. El reto de la biotecnología en este campo es conseguir biocom- 
bustibles baratos a partir de materias primas que no compitan con la alimentación humana. Así, el etanol se puede conseguir a partir de residuos lignocelulósicos de la agricultura (Weber et al., 2010) y el biodiesel a partir microalgas (Pienkos et al., 2012). También se pueden considerar biocombustibles otros compuestos orgánicos producidos por los microorganismos como acetona, alcoholes, alcanos, isoprenoides, etc., y por supuesto el biogas, que es una mezcla gaseosa de metano con otros compuestos. El biogas lo generan los microorganismos mediante digestión anaeróbica de materia orgánica como residuos ganaderos o productos agrícolas y se puede emplear para producir electricidad (Lijó et al., 2014). Tanto los microorganismos como los compuestos químicos y los medios técnicos para producir estos se conocen desde hace tiempo, quedando como un reto de la biotecnología ambiental explotar la biodiversidad microbiana y sus nuevos productos (Timmis et al., 2014). El otro gran objetivo en este campo es mejorar por ingeniería genética las capacidades de los microorganismos disponibles, o generar otros nuevos, que permitan mejorar la eficiencia biotecnológica.

La contaminación puntual de un sitio por el vertido de materia orgánica desequilibra el ciclo del carbono en sentido contrario al del exceso de $\mathrm{CO}_{2}$ atmosférico. Cuando un petrolero vierte su contenido al mar hay que eliminar esa materia orgánica en el menor tiempo posible. En condiciones aeróbicas los microorganismos pueden oxidar la materia orgánica formando $\mathrm{CO}_{2}$ y $\mathrm{H}_{2} \mathrm{O}$ (primer par redox del ciclo del carbono), siempre y cuando estos electrones se transfieran al $\mathrm{O}_{2}$, que se reduce a $\mathrm{H}_{2} \mathrm{O}$ (segundo par redox del ciclo del oxígeno), siendo el proceso exergónico en su conjunto. Por tanto, en estas condiciones el contaminante puede servir tanto como fuente de carbono como de energía para determinados microorganismos. Es importante considerar el número de oxidación de la fuente de carbono puesto que cuanto más reducida esté más energía se puede extraer de ella. Además, es necesario ajustar la reacción redox completa teniendo en cuenta la biomasa y el requerimiento de otros nutrientes. Conocido esto, es necesario modificar las condiciones ambientales, o del medio de cultivo si se actúa ex situ, para ajustarlas a las condiciones teóricas, por ejemplo añadiendo una fuente utilizable de nitrógeno, azufre o fósforo (bioestimulación) o una fuente de carbono o cosustrato (metano) que movilice una comunidad microbiana latente (metanotrofos), con una actividad enzimática (monooxigenasa del metano, MMO) apropiada para la ruta catabólica que se pretende activar (degradación de cadenas hi- drocarbonadas). En este caso, una vez desaparecidos el cosustrato y el contaminante, la comunidad microbiana volverá a su estado latente al cesar el estímulo (Semrau, 2011). La MMO parece estar también implicada en la oxidación anaeróbica de metano por Methylomirabilis oxyfera, proceso que ocurre en aguas dulces procedentes de medios agrícolas sobreabonados acoplado a la reducción de $\mathrm{NO}_{2}{ }^{-}$a $\mathrm{NO}$ por la nitrito reductasa y a la dismutación de $\mathrm{NO}_{\text {a }} \mathrm{N}_{2}$ y $\mathrm{O}_{2}$ por la $\mathrm{NO}$ dismutasa. En el medio marino, la oxidación anaeróbica del metano está ligada a la reducción anaeróbica de $\mathrm{SO}_{4}{ }^{2-}, \mathrm{Fe}^{2+} \mathrm{O} \mathrm{Mn}^{2+}$, posiblemente a través de la reversión de la última etapa de la metanogénesis, lo que constituye un ejemplo extraordinario de confluencia entre ciclos biogeoquímicos (Beal et al., 2009; Knittel y Boetius, 2009).

Otra fuente de desequilibrio carbonado es la producción de alimentos. Aunque la luz que llega a la Tierra desde el sol es de $1.37 \mathrm{~kW} \mathrm{~m}^{-2}$ (en total, $170 \mathrm{PW}$, 1 petawatio $=10^{15} \mathrm{~W}$ ), en promedio queda reducida a $342 \mathrm{~W} \mathrm{~m}^{-2}$ y dado que la atmósfera retiene la mitad de esa energía, llegan aproximadamente $150 \mathrm{~W} \mathrm{~m}^{-2}$ a la superficie terrestre, de los que la fotosíntesis solo es capaz de convertir en nutrientes vegetales menos del $2 \%$, eficiencia que disminuye enormemente por el coste de transformación del nutriente vegetal en carne de vacuno, con una eficiencia del $5 \%$, o de ave, con una eficiencia del $15-20 \%$. Se ha calculado que se necesitan, además, 10 unidades de energía fósil para producir una unidad de energía nutritiva, coste que en USA alcanza el valor de $10 \mathrm{EJ}$ al año (EJ, exajulio $=10^{18}$ J), el $10 \%$ del consumo energético total del país, que en España disminuye hasta el 3\% (Foley, 2011; Webber, 2012). Como sería enormemente difícil aumentar el rendimiento fotosintético, porque habría que operar sobre un sistema metabólico muy complejo, parece más razonable actuar sobre los costes de transformación, procesado y transporte de alimentos así como disminuir la cantidad de desechos generados, el uso de plaguicidas y de abonos nitrógeno-fosforados, algo que cae dentro del ámbito de la biotecnología vegetal y microbiana, dentro de la llamada "Tercera Revolución Verde", que implica el salto a los organismos transgénicos.

Para paliar o evitar el calentamiento global se deben considerar fuentes de energía alternativas a la fósil, entre las que se encuentra la electricidad generada por microorganismos. Las pilas de combustible son una tecnología bastante desarrollada basada en que cualquier reacción redox se puede separar físicamente en dos semirreacciones para producir electricidad 
(Figura 2). Los electrones de la corriente proceden de la oxidación en el ánodo de uno de los pares redox y circulan a través del circuito hasta el cátodo para reducir el otro componente. Si esto se consigue utilizando microorganismos como catalizadores se habrá construido una célula microbiana de combustible (MFC) (Logan et al., 2006). Dada la versatilidad metabólica microbiana, se trata de producir electricidad quemando cualquier tipo de materia orgánica, pero en vez de hacerlo mediante una turbina de vapor, la electricidad se genera directamente a partir de materia orgánica, un proceso en teoría energéticamente mucho más eficiente. La clave está en los microorganismos que catalizan el proceso y permiten, en principio, la utilización de cualquier fuente de carbono, incluidos los contaminantes. Los microorganismos capaces de generar corrientes eléctricas se llaman exoelectrogénicos y entre ellos abundan las proteobacterias, además de Firminutes, acidobacterias, cianobacterias y levaduras. Pueden actuar solos o bien en comunidades sintróficas formando biopelículas en los electrodos (Logan, 2009). Los microorganismos exolectrogénicos son los que utilizan oxidasas terminales de la cadena respiratoria para reducir aceptores como $\mathrm{Fe}^{3+}$ a $\mathrm{Fe}^{2+}$, los que transfieren electrones a otros organismos bien indirectamente mediante $\mathrm{H}_{2} \mathrm{O}$ directamente mediante apéndices conductores o, en tercer lugar, los que transmiten señales eléctricas de quorum sensing.

En una MFC, el potencial del ánodo (-0.2 V) está cerca del potencial del par donante de electrones $\mathrm{CO}_{2} /$ $\mathrm{CH}_{2} \mathrm{O}(-0.3 \mathrm{~V})$, pero la reacción de reducción catódica es fuertemente exergónica dado que el potencial redox del par $\mathrm{O}_{2} / \mathrm{H}_{2} \mathrm{O}$ es $+0.82 \mathrm{~V}$ y el dispositivo genera energía eléctrica.

Producir electricidad en una depuradora de aguas residuales es técnicamente posible y pronto puede ser una realidad. Comparativamente, un humano adulto con un volumen de $0.1 \mathrm{~m}^{3}$ requiere para vivir alrededor de $10.000 \mathrm{MJ}$ por día, lo que equivale al consumo continuo de una bombilla de $100 \mathrm{~W}$. Es decir, $1 \mathrm{~m}^{3}$ de biomasa humana consume aproximadamente $1 \mathrm{~kW}$, mientras que la misma cantidad de biomasa bacteriana, partiendo de un volumen de 0.5

Figura 2. Biocélula de combustible

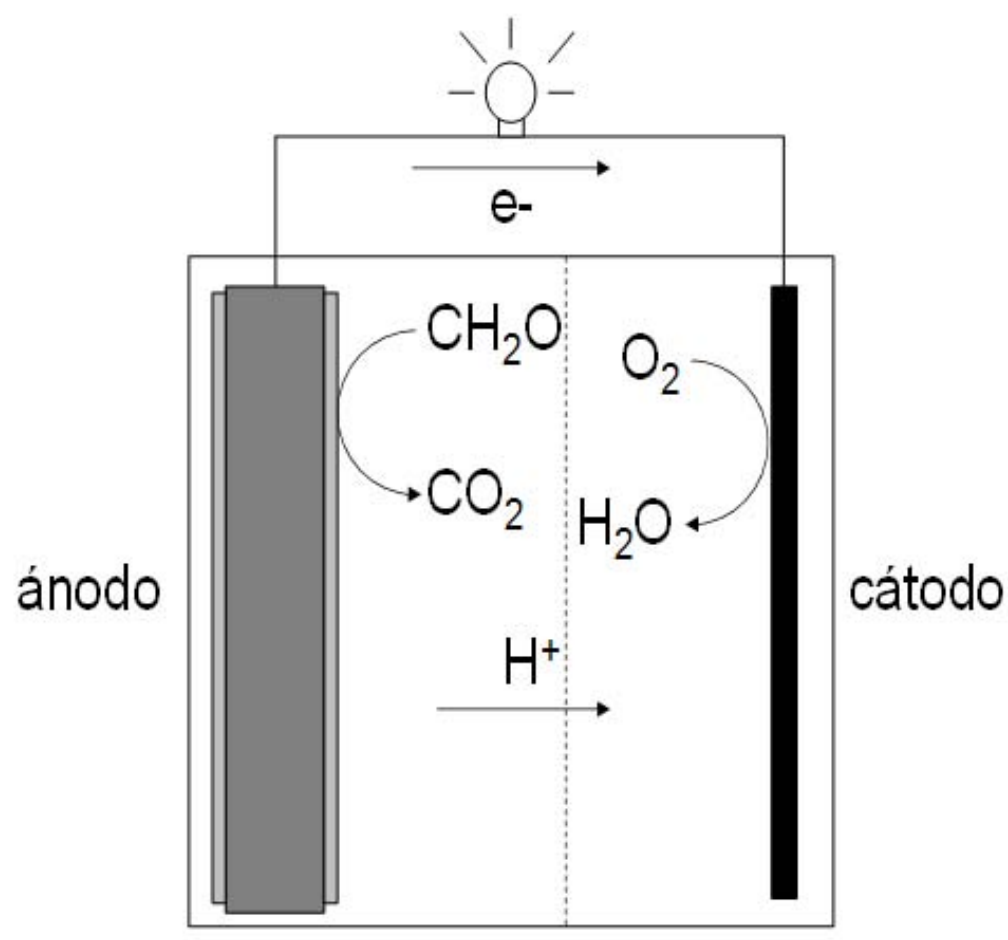

El ánodo es un dispositivo de grafito cubierto por una película microbiana que oxida la materia orgánica y genera electrones que van hacia el cátodo (que también se recubre de biomasa), donde tiene lugar la reducción del $\mathrm{O}_{2}$ a $\mathrm{H}_{2} \mathrm{O}$. El proceso es exergónico porque la diferencia de potencial entre el reductor y el oxidante es mayor de $1 \mathrm{~V}$. El transporte de electrones en el ánodo está facilitado por contacto directo, nanocables bacterianos o mediadores bioquímicos. 
$\mu \mathrm{m}^{3}$ por célula, genera, en teoría, hasta $16 \mathrm{MW}$ de potencia eléctrica (Logan, 2009). Se ha calculado que la recuperación de la energía de las aguas residuales y la biomasa de desecho mediante MFC haría sostenible el sistema de tratamiento de residuos de un país occidental. El problema de las células de combustible microbianas surge de la complejidad en la operación de las mismas y de las pérdidas de corriente, para lo cual se puede aumentar el rendimiento mediante la interposición de condensadores, que reducen la inversión de voltaje y estabilizan este cerca de 1 V, máximo teórico posible (Kim et al., 2011), y/o el acoplamiento de la reacción redox con un proceso de difusión de iones salinos (Logan, 2009).

Otra alternativa sería la producción de hidrógeno (y $\mathrm{CO}_{2}$ ) a partir de la materia orgánica mediante pilas bioelectroquímicas. El hidrógeno podría transportarse y utilizarse para el funcionamiento de cualquier dispositivo movido por una célula de combustible convencional. La descomposición (lisis) de la materia orgánica en $\mathrm{H}_{2}$ y $\mathrm{CO}_{2}$ requiere de la aplicación de un potencial eléctrico externo, dado que se necesita dotar al ánodo de un fuerte potencial oxidante $(+0.5 \mathrm{~V})$ para impulsar la reacción de oxidación del par redox $\mathrm{CO}_{2} / \mathrm{CH}_{2} \mathrm{O}$ donante de electrones (-0.3 V) y permitir que los electrones sean transferidos al cátodo para reducir los $\mathrm{H}^{+}$ a $\mathrm{H}_{2}(-0.42 \mathrm{~V}$ a $\mathrm{pH}$ 7). Evidentemente, la cantidad de energía proporcionada por la posterior combustión del hidrógeno debe ser mayor que la energía consumida por la célula. La clave nuevamente estará en el componente biológico que cataliza el proceso y puede permitir la utilización de infinidad de compuestos carbonados, incluidos compuestos contaminantes o subproductos orgánicos de cualquier tipo. En cuanto al combustible producido en el cátodo puede ser desde $\mathrm{H}_{2}$, hasta $\mathrm{NH}_{3}$ o incluso hidrazina, un combustible utilizado para aviones, vehículos espaciales y cohetes, dependiendo del aceptor de electrones y del tipo de microorganismo presente en el cátodo.

Una variante de las MFC potencia la capacidad microbiana de generar electricidad con la electrodiálisis inversa en un dispositivo llamado MRC utilizando carbonato amónico como sal (Cusick et al., 2012).

Otro tipo de tecnologías trata de transformar compuestos carbonados de desecho, e incluso compuestos tóxicos como el cianuro, en derivados policarbonados que poseen muchas de las propiedades del material plástico pero que por su procedencia biológica son biodegradables. Recientemente, se ha secuenciado el genoma de una bacteria cianotrofa que posee una dotación génica completa para la biosín- tesis de bioplásticos y una gran variedad de sistemas de utilidad biotecnológica desde la biorremediación del cianuro generado en actividades mineras o industriales, hasta el metabolismo del mercurio, los grupos nitroaromáticos o los furfurales. Esto indica la gran utilidad que sigue teniendo el aislamiento de bacterias por enriquecimiento selectivo y el gran futuro de la secuenciación de genomas microbianos como base de la biotecnología (Luque-Almagro et al., 2013). De hecho, los datos metagenómicos serían muy difíciles de interpretar si no se tuviese información funcional previa de rutas metabólicas concretas y de genomas individuales.

\subsection{El ciclo del nitrógeno}

El nitrógeno es un constituyente fundamental de los seres vivos al formar parte de proteínas, lípidos, azúcares, vitaminas y ácidos nucleicos. En las biomoléculas su número de oxidación es - $3\left(\mathrm{R}-\mathrm{NH}_{2}\right)$, mientras que la forma más abundante en la tierra es el $\mathrm{N}_{2}$ atmosférico químicamente muy poco reactivo. El nitrógeno puede adoptar prácticamente todos los estados de oxidación posibles desde -3 a +5 , y en la figura 3 se muestran las reacciones más importantes de su ciclo, incluyendo algunos aportes humanos. El nitrógeno de los compuestos nitroaromáticos, como el trinitrotolueno ( $\left.\mathrm{R}-\mathrm{NO}_{2}\right)$, se suele incorporar al ciclo en forma de nitrito, aunque también lo puede hacer en su forma amino. Sin embargo, en el cianuro y los cianuros orgánicos (nitrilos, R-CN) el nitrógeno ya se encuentra reducido y los microorganismos lo asimilan en forma de amonio. La cantidad de nitrógeno disponible para el crecimiento las plantas es uno de los principales factores limitantes de la productividad de las cosechas. La producción de fertilizantes mediante procesos derivados del de Haber-Bosch, constituyó, junto con la mejora genética, la segunda revolución verde y ha permitido aumentar enormemente la productividad de los cultivos al evitar el paso limitante del ciclo, la fijación biológica de $\mathrm{N}_{2}$, que solo pueden llevar a cabo algunos organismos muy especializados como los rizobios. La producción y empleo de fertilizantes es un parámetro empleado en la medida del desarrollo de una sociedad. En la década de los sesenta, el mayor empleo de fertilizantes tenía Jugar en los países desarrollados (75 kilogramos por hectárea), pero en 2006 Asia Oriental (incluida China) se puso a la cabeza con un valor medio de unos 200 kilogramos por hectárea, cifra que a menudo se multiplicaba por cinco en algunos lugares (Sutton y Bleeker, 2013). Con el actual crecimiento económico y demográfico, para el 2050 la FAO estima un aumento global de 70 por 
ciento de la liberación de nitrógeno al ambiente. Este nitrógeno reactivo causa un enorme desequilibro en el ciclo de nitrógeno que está íntimamente ligado con el resto de los ciclos. Existen extensas revisiones del ciclo del nitrógeno y el tema también ha sido tratado ampliamente con anterioridad (Castillo et al., 2005), por lo que aquí solo se harán algunas puntualizaciones sobre el ciclo resumido en la Figura 3. En primer lugar, las técnicas metagenómicas han permitido descubrir auténticas autopistas del ciclo del nitrógeno que permanecían ocultas por insospechadas y por ser catalizadas por microorganismos desconocidos y no cultivados hasta ahora. La primera de ellas es la ANAMMOX (anaerobic ammonia oxidation), que puede movilizar casi el 50\% de nitrógeno reactivo del mar. En segundo lugar se ha demostrado una reducción anaeróbica del metano en la que el oxidante parece ser el óxido nítrico a través de una dismutación intramolecular a nitrógeno molecular y oxígeno (Figura 3), que actúa como oxidante final del metano. Estos descubri- mientos tienen una enorme repercusión en el conocimiento del funcionamiento del ciclo del nitrógeno, pero también en el diseño de bio-reactores, ya que las formas oxidadas de nitrógeno no solo sirven como comburente para materia orgánica, sino también de otras formas de nitrógeno como el amoniaco. En tercer lugar, el ciclo del nitrógeno también puede ser instructivo en cuanto a biocombustibles. El amoniaco (y la hidracina), junto con el hidrógeno molecular, son los dos únicos bio-combustibles que no producen $\mathrm{CO}_{2}$. El objetivo de la biotecnología sería producirlos a partir de fuentes de energía renovables, lo que quiere decir a partir de la energía solar. Esta idea ya ha sido explorada con anterioridad (Ramos et al., 1984) pero quizá merezca la pena retomarla a la luz de las nuevas tecnologías disponibles. Tampoco se ha de olvidar la biotecnología de otras reacciones del ciclo del nitrógeno, como la fijación simbiótica, asociativa o libre, de $\mathrm{N}_{2}$ a $\mathrm{NH}_{4}^{+}$.

Figura 3. Visión actualizada del ciclo del nitrógeno en la biosfera

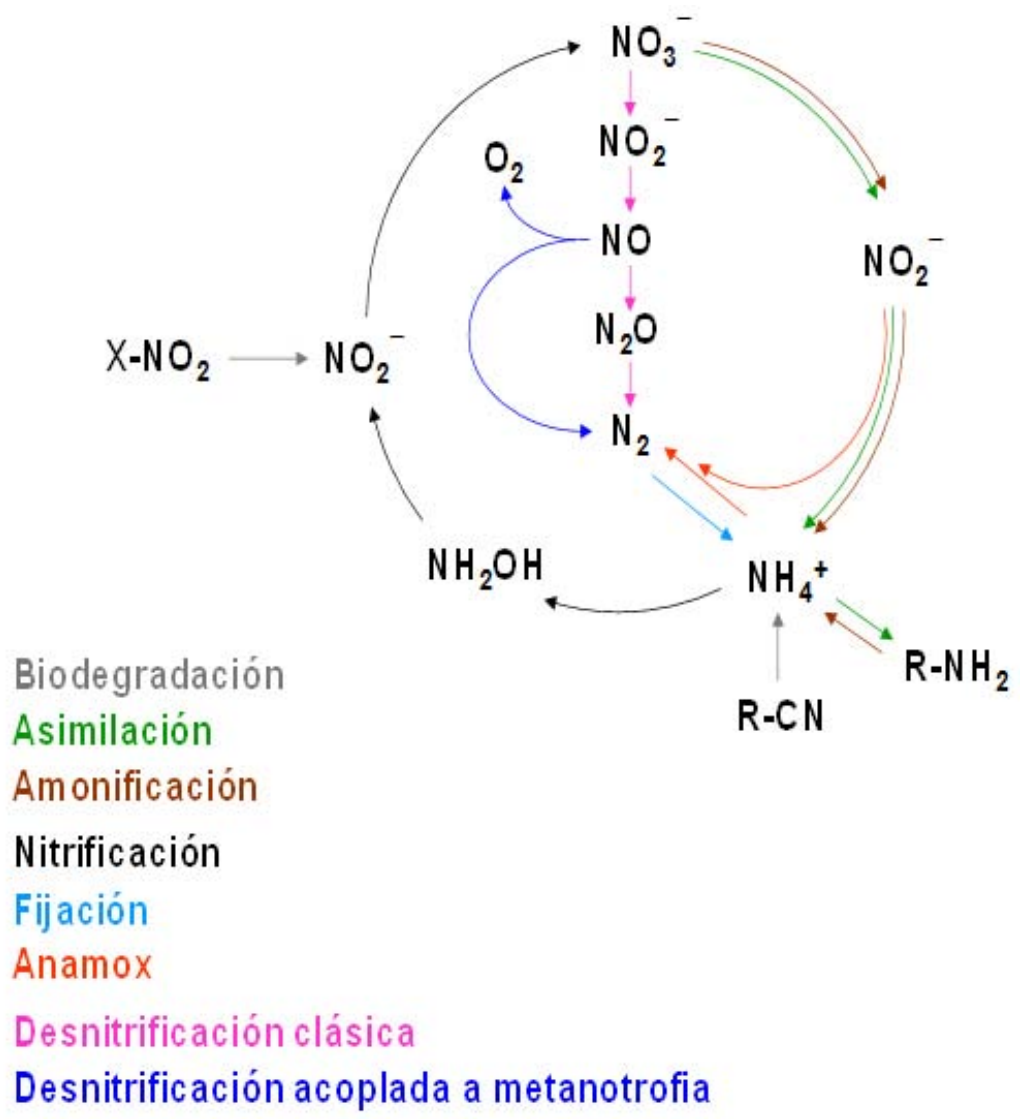

Cada proceso del ciclo está representado por un color. $\mathrm{R}-\mathrm{NH}_{2}$ hace referencia al nitrógeno que forma parte de la biomasa (fundamentalmente proteínas y ácidos nucleicos). R-NO y R-CN representa nitrógeno orgánico de origen antropogénico en forma de compuestos nitrados y cianurados, respectivamente. Las flechas grises representan procesos biodegradativos que devuelven el nitrógeno al ciclo en los puntos indicados. 
La dinámica del nitrógeno atmosférico también obedece a reacciones que implican la formación de especies reactivas a partir de fenómenos eléctricos en la mesosfera, que se manifiestan en forma de figuras luminosas o eventos luminosos transitorios (ELT) observables a simple vista y que se deben a electrones libres atmosféricos cuya energía es proporcional al campo eléctrico reducido o cociente entre el campo eléctrico $\mathrm{E}$ y la densidad de moléculas del aire $(\mathrm{N})$ medido en townsend $\left(10^{-21} \mathrm{~V} \mathrm{~m}^{2}\right)$. A partir de un valor superior a $120 \mathrm{Td}$ se produce lo que se denomina ruptura eléctrica del aire y los procesos de ionización por impacto electrónico, que genera $\mathrm{N}_{2}{ }^{+}$, superan a la captura disociativa de electrones, que produce $\mathrm{O}$ + O- (Luque y Gordillo-Vázquez, 2012). Estas especies químicas, junto con las que se producen por fotólisis del $\mathrm{N}_{2} \mathrm{O}$, como el $\mathrm{O}$ y de este con el $\mathrm{N}_{2} \mathrm{O}$ y $\mathrm{NO}$, controlan la generación del $\mathrm{HO}$, un potente oxidante del metano y de los óxidos de nitrógeno. El NO regula la producción de ozono y su oxidación a $\mathrm{NO}_{2}$ acaba por generar $\mathrm{NO}_{3}^{-}$, un componente de la lluvia ácida (Castillo et al., 2005).

Figura 4. El ciclo del azufre en la biosfera

\subsection{El ciclo del azufre/hierro}

El ciclo natural del azufre es más complejo que el del nitrógeno debido a mayor variedad de especies químicas implicadas con estados de oxidación diferentes así como a su interconexión con los ciclos de metales como el Fe y el $\mathrm{Cu}$. El azufre es muy abundante en la corteza terrestre como sulfuros metálicos (piritas) y sulfato de calcio y magnesio, y especialmente en los océanos, donde existe como sulfatos inorgánicos (1 $\mathrm{mg} \mathrm{L}^{-1}$ ) y sulfuro de dimetilo, DMS, compuesto volátil responsable del olor marino característico y producido a partir del propionato de dimetilsulfonio, principal osmolito del fitoplancton. Anualmente, unas $45 \mathrm{Mt}$ de DMS de origen bacteriano se oxidan fotoquímicamente en la atmósfera a sulfóxido de dimetilo (DMSO), sulfato de metilo y ácido sulfúrico, que actúan como partículas de condensación en la formación de nubes (Castillo et al., 2005).

Entre los procesos redox del ciclo del azufre sobresale la asimilación reductora de sulfato a sulfuro, con sulfito como intermediario, un proceso llevado

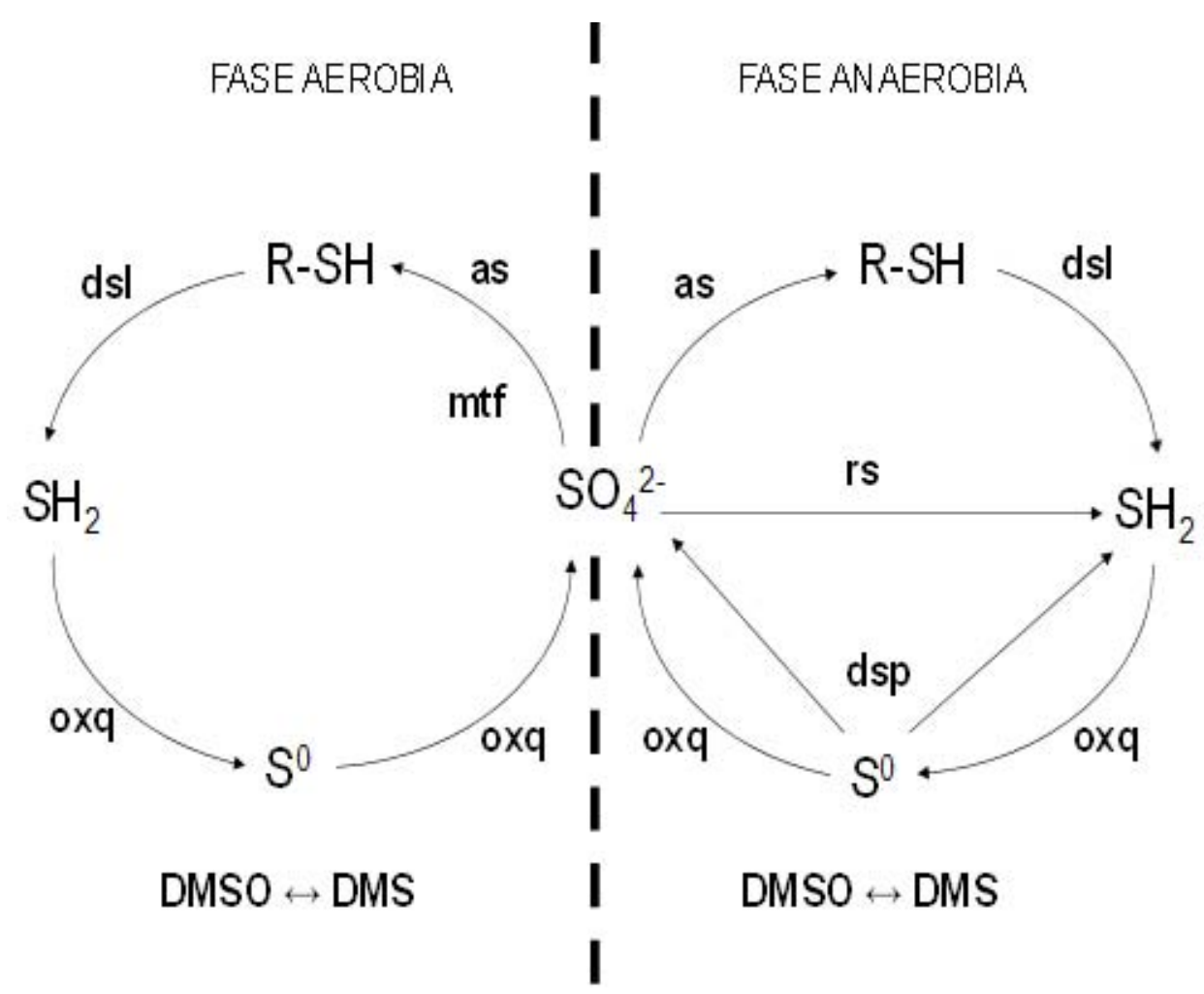

La línea de puntos separa las reacciones que tienen lugar en presencia de oxígeno (izquierda) de las que tienen lugar en anaerobiosis (derecha). R-SH representa el azufre que forma parte de la biomasa. Las abreviaturas son as (asimilación), dsl (desulfurilación), oxq (oxidación quimiolitotrófica), rs (reducción de sulfato), DMSO (sulfóxido de dimetilo), DMS (sulfuro de dimetilo), dsp (desproporción). 
a cabo por microorganismos y plantas y que, dado el potencial muy negativo del par $\mathrm{SO}_{4}{ }^{2-} / \mathrm{SO}_{3}{ }^{2-}$, requiere la activación del sulfato con ATP formando aceptores de electrones como el Adenosín-fosfo-sulfato (APS) y Fosfo-adenosín-fosfo-sulfato (PAPS), el compuesto biológico con mayor energía libre de hidrólisis, cuyo potencial redox es cercano al de los reductores biológicos. Posteriormente, el $\mathrm{S}^{2-}$, muy tóxico, se incorpora como grupo sulfidrilo a la O-acetilserina para dar cisteína. En ambientes anaerobios, sobre todo marinos, las bacterias reductoras de sulfato llevan a cabo la desulfuricación, o reducción respiratoria de $\mathrm{SO}_{4}{ }^{2-} \mathrm{a}$ $\mathrm{S}^{2-}$ con lactato, piruvato o acetato como donantes de electrones utilizando preferentemente el isótopo ${ }^{32} \mathrm{~S}$. Otras bacterias anaerobias reducen ${ }^{0} \mathrm{~S}$ a $\mathrm{S}^{2-}$ o dismutan el $\mathrm{S}_{2} \mathrm{O}_{3}{ }^{2-}$ o el $\mathrm{SO}_{3}{ }^{2-}$ a $\mathrm{SO}_{4}{ }^{2-} \mathrm{y} \mathrm{S}^{2-}$ mediante la enzima rodanasa. Por su parte, el DMS se puede reducir a $\mathrm{S}^{2-} \mathrm{o} \mathrm{CH}_{4}$ por metanógenos u oxidarse a DMSO por bacterias rojas fotosintéticas. Otras bacterias como $E$. coli y Campylobacter utilizan el DMSO como aceptor de electrones respiratorio. El metabolismo del DMS es clave en la detección de productividad oceánica por las aves marinas y en la formación de nubes.

En cuanto a la oxidación microbiana de compuestos azufrados, los sulfuros se oxidan a ${ }^{0} \mathrm{~S}$ o $\mathrm{SO}_{4}{ }^{2-}$ mediante bacterias fototrópicas verdes o rojas, halófilas o desnitrificantes como Thiobacillus. En las fuentes hidrotermales submarinas, el $\mathrm{S}^{2-}$ que acompaña a las emanaciones de $\mathrm{S}^{0}, \mathrm{H}_{2}, \mathrm{NH}_{4}^{+}, \mathrm{NO}_{2}^{-}, \mathrm{Fe}^{2+}, \mathrm{Mn}^{2+}, \mathrm{CH}_{4} \mathrm{y}$ $\mathrm{CO}$ es captado por la hemoglobina del gusano Riftia que junto con el $\mathrm{O}_{2}$, es transportado a bacterias simbióticas del trofosoma, Thiovulum, que oxidan el $\mathrm{S}^{2-} \mathrm{a}$ $\mathrm{S}^{0}$ generando ATP y poder reductor que fija $\mathrm{CO}_{2}$ a carbohidratos utilizados por las células heterótrofas del gusano y también por las branquias de almejas y mejillones presentes en este ecosistema independiente de la luz solar.

En cuanto al hierro, es uno de los elementos más abundantes en la corteza terrestre, bien en la forma $\mathrm{Fe}^{2+} \mathrm{o}$ en la $\mathrm{Fe}^{3+}$, junto con el $\mathrm{Fe}^{0}$ producto de la actividad humana. En ambientes anóxicos predomina la forma soluble $\mathrm{Fe}^{2+}$, mientras que en aerobiosis abunda $\mathrm{Fe}^{3+}$ en forma de hidróxidos insolubles de los que las plantas o los microorganismos extraen hierro mediante sideróforos y complejos sistemas de transporte. En la naturaleza, el $\mathrm{Fe}^{3+}$ de la goetita o la hematita es reducido por microorganismos como Geobacter que oxidan $\mathrm{H}_{2}, \mathrm{~S}^{2-}$ o $\mathrm{S}^{0}$ y también compuestos orgánicos que contaminan acuíferos ricos en $\mathrm{Fe}^{3+}$. Estos microorganismos poseen una reductasa férrica asociada a la membrana y, como sucede con Geobacter sulfu- rreducens, poseen un alto potencial biotecnológico en cuanto a procesos de biorremediación, biominería y en la transferencia de electrones a los electrodos de las células de combustible microbianas.

Por su parte, el $\mathrm{Fe}^{2+}$ es oxidado en aerobiosis y en medios ácidos por Thiobacillus, Leptospirillum y Sulfolobus, muy abundantes en las escorrentías de las minas de carbón. Este proceso genera muy poca energía porque el potencial del par $\mathrm{Fe}^{3+} / \mathrm{Fe}^{2+}$ a $\mathrm{pH}$ ácido es cercano al del par $\mathrm{O}_{2} / \mathrm{H}_{2} \mathrm{O}$ y se genera poco ATP por fosforilación oxidativa. Además, es necesario oxidar grandes cantidades de $\mathrm{Fe}^{2+}$ para producir poder reductor por transporte inverso de electrones, por lo que se producen grandes cantidades de hidróxidos férricos insolubles. Las bacterias oxidadoras de $\mathrm{Fe}^{2+}$ son acidófilos que utilizan el gradiente natural de $\mathrm{H}^{+}$acoplado a la transferencia de electrones al $\mathrm{O}_{2}$ para generar ATP y poder reductor. En anaerobiosis, las bacterias fototrofas oxidan $\mathrm{Fe}^{2+}$ y $\mathrm{S}^{2-}$ para reducir $\mathrm{CO}_{2}$. Otros microorganismos, como la archaea termófila Ferroglobus, acoplan la oxidación del $\mathrm{Fe}^{2+}$ a la reducción de $\mathrm{NO}_{3}{ }^{-}$ (Castillo et al., 2005).

El conocimiento del papel de las bacterias en los ciclos biogeoquímicos de los metales ha llevado a su utilización para la extracción de estos mediante la biotecnología minera. En este proceso de biolixiviación, bacterias como Thiobacillus ferrooxidans oxidan minerales sulfurados liberando $\mathrm{Cu}, \mathrm{Ag}, \mathrm{U}, \mathrm{Ra}$ y otros metales, junto con grandes cantidades de $\mathrm{H}_{2} \mathrm{SO}_{4}$. La biotecnología del Uranio es doblemente interesante tanto por su extracción de menas pobres como de residuos nucleares. El inconveniente es el drenaje ácido de las minas, que contamina fuertemente los acuíferos causando un grave problema ambiental, puesto de manifiesto recientemente en la catástrofe de la balsa de la empresa Boliden en la zona de Aznalcóllar, en la Sierra Norte de Sevilla, España, que comprometió gravemente el equilibrio ecológico del Parque nacional de Doñana. Los estudios metagenómicos de aguas procedentes del drenaje ácido de minas, han revelado una enorme complejidad de microorganismos y rutas metabólicas implicadas (Handelsman, 2004). No cabe duda de que los microorganismos juegan un papel clave en los ciclos biogeoquímicos de los metales, sin embargo, en lo referente al tratamiento de metales in situ las plantas pueden tener una ventaja sobre aquéllos. Los microorganismos pueden cambiar el estado de oxidación de los metales, haciéndolos más o menos bio-disponibles, y también acumularlos actuando como un filtro, pero no eliminarlos del suelo. Sin embargo, las plantas los pueden extraer del suelo 
incorporándolos a su biomasa utilizando la luz como fuente de energía. Por el contrario las plantas pueden parecer en principio inútiles en el tratamiento de la contaminación del suelo por compuestos orgánicos, ya que al ser autótrofas utilizan el carbono oxidado de la atmósfera. Sin embargo las plantas contribuyen a la biodiversidad y vitalidad de los microorganismos del suelo y con ello a la biodegradación de compuestos orgánicos contaminantes, ya que producen exudados que, además de mantener a los microorganismos, en ocasiones actúan como sustratos cometabólicos en la biodegradación de contaminantes. Es decir, las plantas son bioestimulantes de la biodegracación de contaminantes orgánicos. A este proceso, junto con la eliminación de metales, se suele denominar fitorremediación, para distinguirla de la biodegradación mediante microorganismos.

Un proceso de interconexión entre ciclos biogeoquímicos puesto de manifiesto recientemente relaciona los ciclos del azufre y del hierro con la generación de metil-mercurio, una potente neurotoxina que se acumula en la cadena trófica de diferentes medios naturales (Fleming et al., 2006; Gilmour et al., 2011). La correlación positiva entre la producción de metilmercurio y la actividad de bacterias reductoras de $\mathrm{SO}_{4}{ }^{2-}$ y $\mathrm{Fe}^{3+}$ tiene una base molecular consistente en la presencia de los genes $h g c A$, que codifica una proteína con un grupo prostético corrinoide, y $h g c B$, que codifica una proteína con 2 centros 4Fe4S, necesarias para la metilación del mercurio en Desulfovibrio desulfuricans ND 132 y Geobacter sulfurreducens PCA (Parks et al., 2013). La metanogénesis también está relacionada con la producción de metilmercurio, ampliando la interconexión entre ciclos biogeoquímicos y los problemas de contaminación ambiental (Hamelin et al., 2011).

En los sedimentos marinos se produce la transferencia directa de electrones entre microorganismos que forman un filamento de varios $\mathrm{cm}$ de longitud $\mathrm{y}$ que une las reacciones de la capa anóxica más profunda, donde se oxida el $\mathrm{S}^{2-}$ a $\mathrm{S}$, con capas anóxicas superiores donde se reducen iones metálicos (hierro y manganeso) y nitrato, que a su vez transfieren los electrones a microorganismos aeróbicos que utilizan $\mathrm{O}_{2}$ como aceptor. En términos comparativos, la distancia recorrida por los electrones equivaldría a $20 \mathrm{~km}$ para un ser humano (Nielsen et al., 2010). Las bacterias implicadas son de la familia Desulfobulbaceae que forman largos filamentos conductores con células conectadas por canales tubulares periplásmicos. Se piensa que este tipo de conductores podría ser utilizados para eliminar el $\mathrm{H}_{2} \mathrm{~S}$, un gas muy tóxico, o para facilitar la transferencia de electrones en los electrodos de las células microbianas de combustible (Pfeffer et al., 2012).

\section{LLUVIA ÁCIDA Y CAPA DE OZONO}

Durante el metabolismo microbiano se producen emisiones de $\mathrm{SO}_{2}, \mathrm{SH}_{2}$ y $\left(\mathrm{CH}_{3}\right)_{\mathrm{s}}=\mathrm{S}$. Las erupciones volcánicas e hidrotérmicas también contribuyen al aumento del azufre atmosférico $\left(20 \times 10^{12} \mathrm{~g}\right.$ año), mayoritariamente como $\mathrm{SO}_{2}$ que acaba formando $\mathrm{H}_{2} \mathrm{SO}_{4}$ en un proceso catalizado por el radical $\mathrm{HO}$ y el peróxido de hidrógeno. Los óxidos de nitrógeno producidos durante la desnitrificación $\mathrm{N}_{2} \mathrm{O}$ y $\mathrm{NO}$ se emiten a la atmósfera donde acaban como $\mathrm{NO}_{2}$, que también se forma como subproducto de la oxidación del $\mathrm{N}_{2}$ mediante fenómenos eléctricos. Al final, el $\mathrm{NO}_{2}$ acaba formando $\mathrm{HNO}_{3}$ por un proceso similar al que forma $\mathrm{H}_{2} \mathrm{CO}_{3}$ a partir del $\mathrm{CO}_{2}$. La combustión de carbón o petróleo o la tostación de sulfuros minerales pueden provocar la formación de $\mathrm{SO}_{2}$ mientras los gases nitrogenados proceden mayoritariamente de los motores de combustión de automóviles. Para evitar estas emisiones solo queda, además de intentar eliminar estos elementos en un proceso biotecnológico previo a su combustión (García et al., 2007), limitar el consumo de combustibles fósiles y el empleo de fuentes de energía alternativas, como la solar o la eólica. También sería necesario limitar el aporte de óxidos de nitrógeno y azufre operando sobre los ciclos de estos elementos, racionalizando el uso de fertilizantes nitrogenados y evitando las interferencias con el ciclo del azufre en la naturaleza.

Por otra parte, tanto los óxidos de nitrógeno como los derivados fluororocarbonados, el radical $\mathrm{HO}$; los halógenos, los óxidos de nitrógeno y los aerosoles de sulfato reaccionan con el ozono atmosférico, provocando el adelgazamiento de la capa de este gas que filtra la radiación UV y protege la vida de los organismos terrestres. En este sentido, la operación sobre los excesos antropogénicos en los ciclos del nitrógeno y del azufre también podría generar cambios importantes en la gestión de la capa de ozono. Estas operaciones de macroingeniería atmosférica tampoco caen fuera del ámbito de la biotecnología ambiental, aunque rozando ya el área de la tecnología informática para el estudio, manejo y previsión de sistemas complejos (Castillo et al., 2005). 
Beal, E. J., House, C. H. y Orphan, V. J. (2009). "Manganese- and iron-dependent marine methane oxidation". Science, 325, pp. 184-187. http://dx.doi. org/10.1126/science.1169984

Blasco, R., Wittich, R. M., Mallavarapu, M., Timmis, K. N. y Pieper, D. H. (1995). "From xenobiotic to antibiotic, formation of protoanemonin from 4-chlorocatechol by enzymes of the 3-oxoadipate pathway". The Journal of Biological Chemistry, 270, pp. 29229-29235. http:// dx.doi.org/10.1074/jbc.270.49.29229

Castillo, F., Roldán, M., Blasco, R., Huertas, M. J., Caballero, F. J., Moreno-Vivián, C. y Martínez Luque, M. (2005). Biotecnología Ambiental. Madrid: Tébar. http:// dx.doi.org/10.1126/science. 1219330

Cusick, R. D., Kim, Y. y Logan, B. E. (2012). "Energy capture from thermolytic solutions in microbial reverse-electrodialysis cells". Science, 335, pp. 1474-1477.

DaSilva, E. J. (2004). "The Colours of Biotechnology: Science, Development and Humankind". Electronic Journal of Biotechnology, 7, pp. 01-02.

Fleming, E. J., Mack, E. E., Green, P. G. y Nelson, D. C. (2006). "Mercury methylation from unexpected sources: molybdateinhibited freshwater sediments and an iron-reducing bacterium". Applied and Environmental Microbiology, 72, pp. 457-464. http://dx.doi.org/10.1128/ AEM.72.1.457-464.2006

Foley, J. A. (2011). "Can we feed the world \& sustain the planet?". Scientific American, 305, pp. 60-65. http://dx.doi. org/10.1038/scientificamerican1111-60

García, J. L., Santos, V., García-Ochoa, F., García-Calvo, E., Díaz, E., Zamarro, T., Alcón, A., Boltes, K., Letón, P. y Gámez, E. (2007). "Genetic and chemical engineering studies on DBT biodesulphurization". Journal of Biotechnology, 131, pp. S86-S87. http://dx.doi.org/10.1016/j. jbiotec.2007.07.149

Gilmour, C. C., Elias, D. A., Kucken, A. M., Brown, S. D., Palumbo, A. V., Schadt, C. W. y Wall, J. D. (2011). "Sulfate-reducing bacterium Desulfovibrio desulfuricans ND132 as a model for understanding bacterial mercury methylation". Applied and Environmental Microbiology, 77, pp. 3938-3951. http://dx.doi. org/10.1128/AEM.02993-10

Hamelin, S., Amyot, M., Barkay, T., Wang, Y. y Planas, D. (2011). "Methanogens: principal methylators of mercury in lake periphyton". Environmental Science \& Technology, 45, pp. 7693-7700. http:// dx.doi.org/10.1021/es2010072

Handelsman, J. (2004). “Metagenomics: application of genomics to uncultured microorganisms". Microbiology and Molecular Biology Reviews, 68, pp. 669-685. http://dx.doi.org/10.1128/ MMBR.68.4.669-685.2004

Kim, Y., Hatzell, M. C., Hutchinson, A. J. y Logan, B. E. (2011). “Capturing power at higher voltages from arrays of microbial fuel cells without voltage reversal". Energy \& Environmental Science, 4, pp. 4662-4667. http://dx.doi.org/10.1039/ c1ee02451e

Knittel, K. y Boetius, A. (2009). "Anaerobic oxidation of methane: progress with an unknown process". Microbiology. Annual Review of Microbiology, 63, pp. 311-334. http://dx.doi.org/10.1146/annurev.micro.61.080706.093130

Lijó, L., González-García, S., Bacenetti, J., Fiala, M., Feijoo, G., Lema, J. M. y Moreira, M. T. (2014). "Life Cycle Assessment of electricity production in Italy from anaerobic co-digestion of pig slurry and energy crops". Renewable Energy, 68, pp. 625-635. http://dx.doi. org/10.1016/j.renene.2014.03.005

Logan, B. E. (2009). "Exoelectrogenic bacteria that power microbial fuel cells". Nature Reviews Microbiology, 7, pp. 375-381. http://dx.doi.org/10.1038/ nrmicro2113

Logan, B. E., Hamelers, B., Rozendal, R. Schroder, U., Keller, J., Freguia, S., Aelterman, P., Verstraete, W. y Rabaey, K. (2006). "Microbial fuel cells: methodology and technology". Environmental Science \& Technology, 40, pp. 5181-5192. http://dx.doi.org/10.1021/es0605016 http://dx.doi.org/10.1021/es0627592

Luque-Almagro, V. M., Acera, F., Igeño, M. I., Wibberg, D., Roldán, M. D., Sáez, L. P., Hennig, M., Quesada, A., Huertas, M. J., Blom, J., Merchán, F., Escribano, M. P., Jaenicke, S., Estepa, J., Guijo, M. I., Martínez-Luque, M., Macías, D., Szczepanowski, R., Becerra, G., Ramírez, S., Carmona, M. I., Gutiérrez, O., Manso, I., Pühler, A., Castillo, F., Moreno-Vivián, C., Schlüter, A. y Blasco, R. (2013). “Draft whole genome sequence of the cyanide-degrading bacterium Pseudomonas pseudoalcaligenes CECT5344". Environmental Microbiology, 15, pp. 253-270. http://dx.doi.org/10.1111/j.14622920.2012.02875.x

Luque, A. y Gordillo-Vázquez, F. J. (2012). "Mesospheric electric breakdown and delayed sprite ignition caused by electron detachment". Nature Geoscience, 5, pp. 1-4.

Munthali, M. T., Timmis, K. N. y Díaz, E. (1996). "Use of colicin e3 for biological containment of microorganisms". Applied and Environmental Microbiology, 62, pp. 1805-1807.

Nielsen, L. P., Risgaard-Petersen, N., Fossing, H., Christensen, P. B. y Sayama, M. (2010). "Electric currents couple spatially separated biogeochemical processes in marine sediment". Nature, 463, pp. 1071-1074. http://dx.doi.org/10.1038/ nature 08790

Pancost, R. D., Steart, D. S., Handley, L., Collinson, M. E., Hooker, J. J., Scott, A. C., Grassineau, N. V. y Glasspool, I. J. (2007). "Increased terrestrial methane cycling at the Palaeocene-Eocene thermal maximum". Nature, 449, pp. 332-335. http://dx.doi.org/10.1038/ nature06012

Parks, J. M., Johs, A., Podar, M., Bridou, R., Hurt, R. A. Jr., Smith, S. D., Tomanicek, S. J., Qian, Y., Brown, S. D., Brandt, C. C., Palumbo, A. V., Smith, J. C., Wall, J. D., Elias, D. A. y Liang, L. (2013). "The genetic basis for bacterial mercury methylation". Science, 339, pp. 13321335. http://dx.doi.org/10.1126/science. 1230667

Pfeffer, C., Larsen, S., Song, J., Dong, M., Besenbacher, F., Meyer, R. L., Kjeldsen, K. U., Schreiber, L., Gorby, Y. A., El-Naggar, M. Y., Leung, K. M., Schramm, A., Risgaard-Petersen, N. y Nielsen, L. P. (2012). "Filamentous bacteria transport electrons over centimetre distances". Nature, 491, pp. 218-221. http://dx.doi. org/10.1038/nature11586

Pienkos, P., Laurens L. y Aden, A. (2012). "Biocombustibles de microalgas". Investigación y Ciencia, 427, pp. 50-58.

Pla, S. y Catalan, J. (2005). “Chrysophyte cysts from lake sediments reveal the submillennial winter/spring climate variability in the northwestern Mediterranean region throughout the Holocene". Climate Dynamics, 24, pp. 263-278. http:// dx.doi.org/10.1007/s00382-004-0482-1

Ramos, J. L., Guerrero, M. G. y Losada, M. (1984). "Sustained Photoproduction of 
Ammonia from Dinitrogen and Water by the Nitrogen-Fixing Cyanobacterium Anabaena sp. Strain ATCC 33047". Applied and Environmental Microbiology, 48, pp. 114-118.

Semrau, J. D. (2011). "Bioremediation via Methanotrophy: Overview of Recent Findings and Suggestions for Future Research". Frontiers in Microbiology, 2, pp. 1-7. http:// dx.doi.org/10.3389/fmicb.2011.00209

Simon, C. y Daniel, R. (2011). "Metagenomic Analyses: Past and Future Trends". Applied and Environmental Microbiology, 77, pp. 1153-1161. http://dx.doi. org/10.1128/AEM.02345-10
Sutton, M. A. y Bleeker, A. (2013). "Environmental science: The shape of nitrogen to come". Nature, 494, pp. 435-437. http://dx.doi.org/10.1038/ nature11954

Timmis, K., de Lorenzo, V., Verstraete, W., García, J. L., Ramos, J. L., Santos, H., Economidis, I., Nogales, B., Timmis, J. K., Fonseca, C., Pruzzo, C., Karagouni, A., Panopoulos, N. y Dixon, B. (2014). "Pipelines for New Chemicals: a strategy to create new value chains and stimulate innovation-based economic revival in Southern European countries". Environmental Microbiology, 16, pp.
9-18. http://dx.doi.org/10.1111/14622920.12337

Webber, M. E. (2012). "More food, less energy". Scientific American, 306, pp. 74-79. http://dx.doi.org/10.1038/scientificamerican0112-74

Weber, C., Farwick, A., Benisch, F., Brat, D., Dietz, H., Subtil, T. y Boles, E. (2010). "Trends and challenges in the microbial production of lignocellulosic bioalcohol fuels". Applied Microbiology and Biotechnology, 87, pp. 1303-1315. http:// dx.doi.org/10.1007/s00253-010-2707-z 